\title{
Malaria Chemoprophylaxis for Travelers: The Knowledge of Physicians in the State of Qatar, 2017
}

\author{
Ahmad Bawazir ${ }^{1}$, Devendra Bansal ${ }^{2}$, Mohamed Chehab ${ }^{3}$, Ayman Al-Dahshan ${ }^{3}$, Mohamed Bala ${ }^{3}$, Hamad \\ Al-Romaihi ${ }^{4}$, Maha Al-Shamali ${ }^{4}$, Mohamed Al-Hajri ${ }^{4}$, Soha Shawqi Al-Bayat ${ }^{4}$, Mohammed Al-Thani ${ }^{4}$, \\ Elmoubasher Farag ${ }^{*}$
}

${ }^{1}$ Primary Health Care Corporation, Doha, Qatar

${ }^{2}$ Department of Microbiology and Immunology, Weil Cornell Medicine, Doha, Qatar

${ }^{3}$ Community Medicine Residency Program, Hamad Medical Corporation, Doha, Qatar

${ }^{4}$ Ministry of Public Health, Doha, Qatar

Corresponding Author: Elmoubasher Farag, MD, Professor, Department of Public Health, Ministry of Public Health, Doha, Qatar. Tel: +974-50448524, Email: eabdfarag@moph.gov.qa

Received April 16, 2018; Accepted May 13, 2018; Online Published May 15, 2018

\begin{abstract}
Introduction: Malaria is among the most significant travel-related infections encountered by travelers to endemic countries in terms of morbidity and mortality. In Qatar, imported malaria has increased over the last 5 years; 493 travel-related cases were confirmed in 2016. In the current study, the knowledge of malaria chemoprophylaxis among physicians in the State of Qatar was assessed.

Methods: This was a cross-sectional study conducted during a national travel health workshop at the Ministry of Public Health, Qatar. Physicians participating in the workshop from different national healthcare institutions providing travel medicine services were invited to voluntarily complete a self-administered, structured questionnaire.

Results: Forty-two medical doctors participated in the study (92 response rate). Based on their specialty, almost two-thirds (64.3\%) of the participants were family medicine physicians, and one-fifth (21.43\%) were general practitioners. Furthermore, most of the doctors were untrained in travel medicine. The majority of participants demonstrated a good knowledge of the malaria parasite (100\%), Plasmodium species $(64.3 \%)$, incidence $(83.3 \%)$, transmission (66.7\%), and drug-resistance (95.2\%) of malaria. Additionally, most physicians (>90) were knowledgeable about the major features of severe or complicated malaria as well as malaria prevention and chemoprophylaxis.

Conclusion: This study highlights several areas of good knowledge on travel-related malaria prophylaxis and prevention among the study participants; however, there are still a few knowledge gaps that require mitigation. Continuing training programs on malaria prevention in travelers will sustain this good level of knowledge among physicians and improve the quality of pre-travel advice provided by travel medicine practitioners in Qatar.
\end{abstract}

Keywords: Chemoprevention, Malaria, Travel Medicine, Qatar

Citation: Bawazir A, Bansal D, Chehab M, et al. Malaria chemoprophylaxis for travelers: the knowledge of physicians in the State of Qatar, 2017 Int J Travel Med Glob Health. 2018;6(2):69-75. doi:10.15171/ijtmgh.2018.13.

\section{Introduction}

Malaria is the world's most widely spread febrile illness. Globally, around 302 million people are at risk of malaria, with 216 million new cases and 445000 deaths (compared to 446,000 deaths in 2015) attributed to malaria annually. The African region contributed $91 \%$ of global malaria cases followed by the Southeast Asian (6\%) and Eastern Mediterranean regions (2\%). The majority of deaths occur among young children, pregnant women, non-immune travelers, refugees, displaced persons, and laborers traveling to endemic areas. ${ }^{1}$ Moreover, it is well known that those visiting friends and relatives (VFR) are at high risk of malaria as they are less likely to use chemoprophylaxis. ${ }^{2}$

Imported malaria is currently one of the major threats to the significant achievement of global malaria control, ${ }^{3}$ which has led to a substantial reduction in morbidity and mortality in high transmission areas and interruption of transmission in low transmission areas. Though indigenous transmission of malaria has been eliminated in most of the Gulf Cooperation Council (GCC) countries, a large number of imported malaria cases occur, especially among the sizeable migrant workforces in these countries. ${ }^{4}$ The majority of these workers come from the Indian subcontinent, while the remaining cases are from sub-Saharan African countries, including Sudan, Ethiopia,

Copyright $(\subset 2018$ The Author(s). This is an open-access article distributed under the terms of the Creative Commons Attribution License (http:// creativecommons.org/licenses/by/4.0), which permits unrestricted use, distribution, and reproduction in any medium, provided the original work is properly cited. 
Kenya, and Tanzania. ${ }^{5-7}$ The Arabian Gulf countries lie at the fringes of malaria endemicity, and local disease transmission in the area has been interrupted because of sustained vector control. $^{8}$

Rigorous control interventions in the 1960-1970s resulted in a malaria-free status for most countries of the GCC, with the exceptions of Saudi Arabia and Yemen. ${ }^{9}$ The WHO certification of malaria-free status is indicative of sustained elimination of indigenous malaria transmission for at least three consecutive years. However, the constant influx of imported malaria cases from endemic countries represents a direct threat to the aforementioned success. ${ }^{10}$

In Qatar, malaria transmission has been interrupted since the $1970 \mathrm{~s}^{7}$; however, the incidence of imported malaria increased more than two-fold in 2005 and 2006 after a lengthy consistent decrease. ${ }^{11}$ The majority of cases were male, nonQatari, and aged 15 years or above. Plasmodium vivax was the main etiologic agent in half of the cases, and most incidences occurred between August and October, which confirms the importation of infection from endemic countries during the summer vacation. ${ }^{11,12}$ Hence, the present study recommends that efforts be introduced to educate travelers about malaria prophylaxis and other preventive measures.

Recently, the Ministry of Public Health-Qatar (MOPH) received a total of 493 confirmed malaria cases among travelers. The number of reported cases was found to be higher among the non-Qatari population (98.2\%). The gender distribution was considerably higher among male (89.9\%) than female travelers $(10.1 \%) .{ }^{13}$

The indigenous malaria transmission has been eliminated in Qatar, but the risk of imported malaria still exists due to the large influx of immigrant workers from the Indian subcontinent and Sub-Saharan Africa posing a risk for malaria re-introduction. ${ }^{7,11}$ Additionally, the country is liable to malaria reintroduction because of the presence of two potential malaria vectors Anopheles stephensi and $A$. multicolor. ${ }^{14}$

Malaria is a serious disease with no effective vaccine available yet. ${ }^{2,15}$ Therefore, malaria prevention is vital and consists of protective measures against mosquito bites as well as chemoprophylaxis use. ${ }^{16-19}$ Chemoprophylaxis is one of the main preventive interventions employed in the field of travel medicine to avoid clinical manifestations and protect against the development of severe illness and death. ${ }^{18}$ Depending on the level of risk, it may be appropriate to advise no specific interventions, mosquito avoidance measures only, or mosquito avoidance measures plus chemoprophylaxis. ${ }^{15}$

It has been demonstrated that malaria infection should be considered in the differential diagnosis of patients presenting with a recent travel history to malaria-endemic countries as well as in patients with fever of unknown origin. ${ }^{20}$ To be effective, malaria chemoprophylaxis has to be taken regularly by travelers. In addition, previous studies have shown that poor compliance is a common problem among travelers because of peer pressure to avoid taking the chemoprophylaxis as well as adverse drug reactions. Thus, travel practitioners should be prepared to address the above-mentioned barriers, especially for long-term travelers. Malaria prevention is a complex issue and requires expert, individualized advice from travel medicine specialists. ${ }^{21,22}$ In the era of malaria elimination, the knowledge and practices of health professionals and travelers regarding chemoprophylaxis are important for preventing the reintroduction of malaria. ${ }^{23}$ Travel to malaria-endemic regions requires specific preparation to avoid illness. A primary care doctor might serve the aforementioned task, but constantly changing and highly specialized information renders a dedicated travel medicine expert more likely to succeed in handling the individual needs of different travelers as well as their unique travel itineraries. ${ }^{24}$

Only a few studies have assessed the knowledge and practice of physicians regarding malaria chemoprophylaxis, and the information relevant to malaria surveillance in Qatar remains inadequate to give a clear epidemiological picture for developing a national malaria control strategy. In addition, the lack of standardized national guidelines on malaria chemoprophylaxis puts the country at risk of such disease and necessitates a robust surveillance system and preparedness to address any potential outbreaks. Thus, in the present study, physicians' knowledge of travel-related malaria chemoprophylaxis in Qatar was assessed in an attempt to stall the potential spread of this deadly infection in the country.

\section{Methods}

Study Area

This cross-sectional study was carried out in 2017 at the $\mathrm{MoPH}$, Doha, Qatar. Before the beginning of a national-level workshop at $\mathrm{MoPH}$ about travel health, 50 participants from primary health care centers (PHCC), Qatar's Red Crescent Society (QRCS), and Hamad Medical Corporation (HMC) were invited to complete a self-administered questionnaire.

\section{Data Collection}

A structured questionnaire was developed to assess the knowledge of physicians regarding malaria chemoprophylaxis use among travelers. The questionnaire was composed of four main sections: the first gathered demographic data, while the rest were related to the knowledge of physicians regarding the risk of malaria during travel, symptomatology of severe malaria, malaria prevention advice for travelers, and chemoprophylaxis among travelers. Moreover, the survey included 14 questions and required approximately 15 minutes to complete. The initial section of the questionnaire elicited general information about the respondents regarding gender, age, specialty, year of practice, and type of employing healthcare facility. After that, participants were asked about any previous training related to travel health. The questionnaire also explored the physicians' knowledge of the hazards imposed by malaria on travelers. Furthermore, the participants' tested areas of knowledge included mode of malaria transmission, travel characteristics associated with malaria cases, symptoms of malaria after return, and Plasmodium antimalarial resistance. Physicians were also asked about malaria prophylaxis, including the administration, indications, contraindications, and type of advice given in relation to specific destinations. The participants had to respond in a true or false format. The survey also questioned physicians on their current practices 
regarding malaria chemoprophylaxis for travelers.

To develop the questionnaire, the researchers conducted a review of the literature to include previous evidence on travel-related malaria chemoprophylaxis as well as on the knowledge, attitude, and practice of physicians regarding this issue. An English-based questionnaire was reviewed and validated using the face validation method. Afterwards, the questionnaire was piloted for final revisions or alterations.

\section{Sampling}

The current study was conducted during a nationwide workshop at the MoPH, Qatar, for physicians from different governmental healthcare organizations. Thus, a convenient sampling technique was employed, in which the attendees were invited to complete a self-administered questionnaire.

\section{Data Analysis}

Data was entered into Microsoft Excel, and analysis was carried out in JMP version 10.0 (SAS Institute, USA). Descriptive statistics were employed as appropriate, such as proportions and percentages for categorical variables or means and standard deviations for continuous variables. All $P$ values less than or equal to 0.05 were considered to be statistically significant.

\section{Results}

Demographic Characteristics of the Study Participants

A total of 42 (92\%) physicians working in three healthcare institutions participated in the study. The majority of participants were males (65.8\%), non-Qataris (85.0\%), and lacked training in travel medicine. The demographics of the study participants are summarized in Table 1, which shows that almost three-quarters (76.2\%) of the physicians were employed at the Primary Health Care Corporation (PHCC). Additionally, based on their specialty, about two-thirds $(64.3 \%)$ of the participants were family medicine physicians and one-fifth $(21.43 \%)$ were general practitioners. According to the level of education, more than two-thirds (69\%) were specialists and a quarter (26.2\%) were resident physicians.

Knowledge of the Study Participants Regarding TravelRelated Malaria

The general knowledge of physicians regarding malaria and risk of transmission during travel is shown in Table 2. The majority of participants knew of the malaria parasite, Plasmodium species, malaria incidence, transmission, and drug-resistance. In addition, the majority (>90\%) of surveyed physicians knew about the major features of severe or complicated malaria, such as impaired consciousness or seizures, severely decreased hemoglobin level (less than $8 \mathrm{~g}$ / $\mathrm{dL}$ ), disseminated intravascular coagulation and spontaneous bleeding, and hemoglobinuria (Table 3).

Table 4 shows the knowledge of physicians regarding vital factors in the prevention of malaria among travelers. Most respondents were knowledgeable about the importance of eliciting a thorough medical history from travelers, especially the itinerary, health condition, duration and nature of the travel. Additionally, the physicians portrayed a good level of

\begin{tabular}{|c|c|c|}
\hline Variables & Response & No. $(\%)$ \\
\hline \multirow{3}{*}{ Institutions } & PHCC & $32(76.2)$ \\
\hline & HMC & $5(11.90)$ \\
\hline & QRC & $5(11.90)$ \\
\hline \multirow{4}{*}{ Specialty } & Family medicine & $27(64.29)$ \\
\hline & General practitioner & $9(21.43)$ \\
\hline & Pediatrician & $1(2.38)$ \\
\hline & Emergency medicine & $5(11.90)$ \\
\hline \multirow{2}{*}{ Gender } & Male & $27(65.85)$ \\
\hline & Female & $14(34.15)$ \\
\hline \multirow{2}{*}{ Obtained travel medicine training } & Yes & $6(15.0)$ \\
\hline & No & $34(85.0)$ \\
\hline \multirow{2}{*}{ Nationalities } & Qatari & $6(15.0)$ \\
\hline & Non-Qatari & $34(85.0)$ \\
\hline \multirow{3}{*}{ Specialties and education level } & Resident & $11(26.2)$ \\
\hline & Specialist & $29(69.0)$ \\
\hline & Consultant & $2(4.8)$ \\
\hline
\end{tabular}

Abbreviations: PHCC, Primary Health Care Corporations; HMC, Hamad Medical Corporations; QRC, Qatar Red Crescent.

knowledge regarding strategies and methods for preventing malaria among travelers of different subgroups.

Most physicians had a comprehensive knowledge about malaria prophylaxis for travelers. In addition, most physicians knew about the indications and administration details for several widely used antimalarial agents, such as doxycycline, atovaquone plus proguanil, chloroquine, and mefloquine (Table 5). The participants' knowledge regarding the specific chemoprophylactic regimen for each of the aforementioned antimalarial medications is shown in Table 6 and includes the frequency, pre-travel administration of medication, and post travel intake of chemoprophylaxis.

\section{Discussion}

In the era of malaria elimination, knowledge regarding malaria chemoprophylaxis among physicians is vital for preventing any reintroduction of the disease. ${ }^{23} \mathrm{~A}$ primary healthcare provider can be an excellent source of guidance when making decisions concerning chemoprophylaxis. ${ }^{15}$ However, in reality, this might not be the case. A study by the CDC found that primary care physicians could not completely prepare their patients in this regard. ${ }^{25}$

In the present study, the majority $(84 \%)$ of physicians working in the different healthcare institutions participated in the survey, which is an excellent response rate and considered satisfactory for reflecting the level of knowledge among physicians in Qatar.

All study participants were physicians, because only physicians are allowed to practice travel medicine in Qatar; however, in the United Kingdom and Taiwan, nurses account for the majority of travel medicine practitioners, $97 \%$ and $70 \%$, respectively. ${ }^{26,27}$

In the current study, the majority $(85.0 \%)$ of participants 
Table 2. Risk of Malaria Transmission During Travel

\begin{tabular}{|c|c|c|c|}
\hline Questions & True, No. $(\%)$ & False, No. $(\%)$ & Unanswered, No. $(\%)$ \\
\hline $\begin{array}{l}\text { Malaria is a serious febrile disease due to infection of red blood cells with a parasite called } \\
\text { Plasmodium. }\end{array}$ & $42(100.0)$ & $0(0.0)$ & $0(0)$ \\
\hline Five species of Plasmodium regularly infect humans; it is transmitted by mosquitoes. & $28(66.7)$ & $14(33.3)$ & $0(0)$ \\
\hline $\begin{array}{l}\text { Plasmodium malariae is the most dangerous species of malaria parasite; the vast majority of } \\
\text { malaria deaths worldwide happen due to it. }\end{array}$ & $15(35.7)$ & $27(64.3)$ & $0(0)$ \\
\hline Chloroquine-resistant falciparum malaria is now widespread. & $40(95.2)$ & $2(4.8)$ & $0(0)$ \\
\hline The number of infectious bites received influences exposure of travelers to malaria. & $31(73.8)$ & $10(23.8)$ & $1(2.4)$ \\
\hline $\begin{array}{l}\text { The optimum conditions for malaria transmission are temperature range }\left(20-30^{\circ} \mathrm{C}\right) \text { and high } \\
\text { humidity. }\end{array}$ & $33(78.6)$ & $7(16.7)$ & $2(4.7)$ \\
\hline Malaria incidence is generally higher in urban than rural regions. & $7(16.7)$ & $35(83.3)$ & $0(0)$ \\
\hline Malaria transmission is higher during the day than between dusk and dawn. & $6(14.3)$ & $36(85.7)$ & $0(0)$ \\
\hline
\end{tabular}

Table 3. The Important Features of Severe falciparum Malaria in Adults

\begin{tabular}{|c|c|c|c|}
\hline Questions & True, No. $(\%)$ & False, No. $(\%)$ & Unanswered, No. (\%) \\
\hline Impaired consciousness or seizures & $41(97.6)$ & $1(2.4)$ & $0(0)$ \\
\hline Hemoglobin less than $8 \mathrm{~g} / \mathrm{dL}$ & $39(92.9)$ & $2(4.7)$ & $1(2.4)$ \\
\hline Disseminated Intravascular Coagulation (DIC) - Spontaneous bleeding & $38(90.5)$ & $4(9.5)$ & $0(0)$ \\
\hline Hemoglobinuria without G6PD deficiency & $36(85.7)$ & $6(14.3)$ & $0(0)$ \\
\hline The traveler's destination & $41(97.6)$ & $1(2.4)$ & $0(0)$ \\
\hline
\end{tabular}

Table 4. Knowledge of the Factors That Need to Be Considered by the Doctors When Advising for the Prevention of Malaria

\begin{tabular}{|c|c|c|c|c|}
\hline & Factors That Need to Be Considered by Doctors & True, No. (\%) & False, No. $(\%)$ & Unanswered, No. (\%) \\
\hline \multirow{8}{*}{$\begin{array}{l}\text { Factors that need to } \\
\text { be considered by the } \\
\text { doctor when advising } \\
\text { for malaria prevention } \\
\text { among travelers }\end{array}$} & Destination & $41(97.6)$ & $1(2.4)$ & $0(0)$ \\
\hline & Traveling nature & $40(95.2)$ & $2(4.8)$ & $0(0)$ \\
\hline & Duration of stay & $42(100.0)$ & $0(0.0)$ & $0(0)$ \\
\hline & Antimalarial effectiveness/Potential adverse effects & $41(97.6)$ & $1(2.4)$ & $0(0)$ \\
\hline & Health condition/status of the traveler & $42(100.0)$ & $0(0.0)$ & $0(0)$ \\
\hline & Compliance issues & $41(97.6)$ & $1(2.4)$ & $0(0)$ \\
\hline & Malarial parasites susceptibility to commonly used chemoprophylaxis & $40(95.2)$ & $2(4.8)$ & $0(0)$ \\
\hline & $\begin{array}{l}\text { Availability of good quality medical care and reliable diagnostic tests for } \\
\text { malaria }\end{array}$ & $36(85.7)$ & $6(14.3)$ & $0(0)$ \\
\hline \multirow{3}{*}{$\begin{array}{l}\text { Strategies for malaria } \\
\text { prevention include }\end{array}$} & Measures of mosquito avoidance & $42(100.0)$ & $0(0.0)$ & $0(0)$ \\
\hline & Antimalarial chemoprophylaxis & $42(100.0)$ & $0(0.0)$ & $0(0)$ \\
\hline & Homoeopathic or 'natural' antimalarial prophylaxis & $22(52.4)$ & $19(45.2)$ & $1(2.4)$ \\
\hline \multirow{4}{*}{$\begin{array}{l}\text { Prevention of malaria } \\
\text { among travelers }\end{array}$} & It is complex. & $31(73.9)$ & $8(19)$ & $3(7.1)$ \\
\hline & $\begin{array}{l}\text { There is no risk of malaria transmission to } 1 \mathrm{st} \text { or } 2 \text { nd generation immigrants } \\
\text { living in non-endemic areas who return to their home countries. }\end{array}$ & $10(23.8)$ & $32(76.2)$ & $0(0)$ \\
\hline & $\begin{array}{l}\text { For destinations with sporadic and low risk for infection, it is recommended } \\
\text { that mosquito avoidance measures without chemoprophylaxis be used. }\end{array}$ & $25(59.5)$ & $17(40.5)$ & $0(0)$ \\
\hline & $\begin{array}{l}\text { For areas where } P \text {. vivax is the predominant species of malaria parasite } \\
\text { present, in addition to mosquito avoidance interventions, primaquine is a } \\
\text { good option as a main prophylaxis for those who aren't G6PD deficient. }\end{array}$ & $33(78.6)$ & $9(21.4)$ & $0(0)$ \\
\hline
\end{tabular}

did not receive any training in travel health in contrast with participants of studies from Germany and Greece, where 64 and 60 of health professionals were well trained. ${ }^{28,29}$ Furthermore, the present study revealed a good level of knowledge about malaria prophylaxis and the administration of antimalarials among healthcare providers. There was poor knowledge in certain areas, however, attributable to the fact that most participants had not attended any training in travel 
Table 5. Knowledge of Malarial Chemoprophylaxis Among Study Physicians in the State of Qatar

\begin{tabular}{|c|c|c|c|c|}
\hline Chemoprophylaxis & Antimalarial Agents, Indications, and Administration & True, No. $(\%)$ & False, No. $(\%)$ & Unanswered, No. $(\%)$ \\
\hline \multirow{4}{*}{$\begin{array}{l}\text { Malaria } \\
\text { chemoprophylaxis }\end{array}$} & $\begin{array}{l}\text { In addition to primary prophylaxis, presumptive anti-relapse therapy is } \\
\text { used after exposure period to prevent hypnozoites of } P \text {. vivax or } P \text {. ovale. }\end{array}$ & $37(88.1)$ & $4(9.5)$ & $1(2.4)$ \\
\hline & $\begin{array}{l}\text { Primaquine cannot be used for a patient who has not been tested for } \\
\text { G6PD. }\end{array}$ & $33(84.6)$ & $6(15.4)$ & $3(7.1)$ \\
\hline & $\begin{array}{l}\text { Chemoprophylaxis options for areas with chloroquine-resistant malaria } \\
\text { are atovaquone-proguanil, doxycycline, and mefloquine. }\end{array}$ & $40(95.2)$ & $1(2.4)$ & $1(2.4)$ \\
\hline & $\begin{array}{l}\text { Chemoprophylaxis options for areas where mefloquine-resistant } \\
\text { malaria is present are atovaquone-proguanil and doxycycline. }\end{array}$ & $37(88.1)$ & $4(9.5)$ & $1(2.4)$ \\
\hline \multirow{4}{*}{ Doxycycline } & $\begin{array}{l}\text { Doxycycline is considered to be an effective chemoprophylaxis for } \\
\text { chloroquine-resistant } P \text {. falciparum malaria. }\end{array}$ & $24(57.2)$ & $16(38.1)$ & $2(4.7)$ \\
\hline & $\begin{array}{l}\text { Doxycycline is recommended as a prophylaxis for pregnant or } \\
\text { breastfeeding travelers. }\end{array}$ & $7(16.7)$ & $34(80.9)$ & $1(2.4)$ \\
\hline & $\begin{array}{l}\text { Doxycycline can provide some protection against leptospirosis, some } \\
\text { STIs (e.g., chlamydia), and infectious diarrhea. }\end{array}$ & $38(90.5)$ & $3(7.1)$ & $1(2.4)$ \\
\hline & $\begin{array}{l}\text { Doxycycline should be swallowed whole with plenty of fluids during } \\
\text { meals while sitting or standing. }\end{array}$ & $33(80.5)$ & $8(19.5)$ & $1(2.4)$ \\
\hline \multirow{4}{*}{$\begin{array}{l}\text { Atovaquone plus } \\
\text { proguanil combination } \\
\text { (Malarone }(\mathbb{R})\end{array}$} & $\begin{array}{l}\text { As a prophylaxis, the atovaquone plus proguanil combination is well } \\
\text { tolerated. }\end{array}$ & $33(80.5)$ & $8(19.5)$ & $1(2.4)$ \\
\hline & $\begin{array}{l}\text { The atovaquone plus proguanil combination acts as a suppressive } \\
\text { prophylactic agent, so it should be continued for only } 7 \text { days after } \\
\text { leaving malaria risk areas. }\end{array}$ & $36(85.8)$ & $4(9.5)$ & $2(4.7)$ \\
\hline & $\begin{array}{l}\text { The atovaquone plus proguanil combination will not protect against } \\
\text { hypnozoite-induced episodes of } P \text {. vivax or } P \text {. ovale malaria. }\end{array}$ & $28(66.7)$ & $12(28.6)$ & $2(4.7)$ \\
\hline & $\begin{array}{l}\text { The atovaquone plus proguanil combination should not be used as an } \\
\text { antimalarial chemoprophylaxis during pregnancy and breast feeding. }\end{array}$ & $25(62.5)$ & $15(37.5)$ & $2(4.7)$ \\
\hline \multirow{4}{*}{ Chloroquine } & The resistance of $P$. falciparum parasites limits the use of chloroquine. & $39(95.1)$ & $2(4.9)$ & $1(2.4)$ \\
\hline & $\begin{array}{l}\text { Chloroquine should not be prescribed for pregnant women or young } \\
\text { children. }\end{array}$ & $24(57.1)$ & $12(28.6)$ & $6(14.3)$ \\
\hline & $\begin{array}{l}\text { The effectiveness of the intradermal rabies vaccine is reduced by } \\
\text { chloroquine, so it should be given by the intramuscular route. }\end{array}$ & $29(69)$ & $12(28.6)$ & $1(2.4)$ \\
\hline & $\begin{array}{l}\text { P. falciparum chloroquine-resistant malaria exists in all regions except } \\
\text { some countries in the Middle East, Central America, the Caribbean, } \\
\text { and west of the Panama Canal. }\end{array}$ & $31(73.8)$ & $10(23.8)$ & $1(2.4)$ \\
\hline \multirow{4}{*}{ Mefloquine (Lariam) } & $\begin{array}{l}\text { In regions where chloroquine-resistant } P \text {. falciparum is prevalent, } \\
\text { mefloquine is a very effective prophylaxis }\end{array}$ & $36(85.7)$ & $6(14.3)$ & $0(0)$ \\
\hline & Weekly use of mefloquine positively helps compliance. & $38(90.5)$ & $4(9.5)$ & $0(0)$ \\
\hline & $\begin{array}{l}\text { Travelers who have used mefloquine as a chemoprophylaxis can also } \\
\text { use it for self-treatment. }\end{array}$ & $30(71.4)$ & $12(28.6)$ & $0(0)$ \\
\hline & $\begin{array}{l}\text { Mefloquine is contraindicated in those with a current or previous } \\
\text { history of depression, neuropsychiatric disorders, or epilepsy. }\end{array}$ & $31(73.8)$ & $11(26.2)$ & 0 \\
\hline
\end{tabular}

health. This was evident in some of their answers. Only a few doctors were unaware of the five species of Plasmodium, and a similar portion (14.3\%) had no knowledge about the risk of malaria transmission, which is highest at dusk and dawn.

The average score regarding the general knowledge of malaria in previous studies was more than $80 . .^{30,31}$ Additionally, the average correct score on knowledge of anti-malaria prophylaxis ranged from $52.9 \%$ to $98.5 \% .{ }^{29}$ The participants' knowledge about the major features of complicated falciparum malaria in adults was significant as was their knowledge concerning malaria prevention advice for those traveling to endemic areas.

\section{Conclusion}

The current study highlighted several competency areas of knowledge among physicians in Qatar regarding malaria prophylaxis and prevention. However, there are still a few knowledge gaps which demand mitigation. National guidelines for malaria prophylaxis and prevention strategies in travelers are needed with the active dissemination of this information among various healthcare workers to maintain a high level of knowledge. Mandatory continuing professional development programs are also necessary in Qatar. Similarly, training provided by recognized travel health institutions would significantly support the practice of travel medicine in 
Table 6. Characteristics of Recommended Prophylactic Antimalarials in the State of Qatar

\begin{tabular}{|c|c|c|c|c|c|c|}
\hline \multirow{3}{*}{$\begin{array}{l}\text { Antimalarial } \\
\text { Chloroquine } \\
\text { Response }\end{array}$} & \multicolumn{2}{|c|}{ Frequency } & \multicolumn{2}{|c|}{ Time Before Entering a Malarial Risk Area } & \multicolumn{2}{|c|}{ Time After Departure From a Malarial Risk Area } \\
\hline & \multicolumn{2}{|c|}{ Weekly } & \multicolumn{2}{|c|}{1 Week } & \multicolumn{2}{|c|}{4 Weeks } \\
\hline & Yes & No & Yes & No & Yes & No \\
\hline Frequency & 31 & 8 & 33 & 8 & 32 & 6 \\
\hline Percentage & 79.5 & 20.5 & 86.8 & 13.2 & 84.2 & 15.8 \\
\hline Total $(\mathrm{n})$ & \multicolumn{2}{|c|}{39} & \multicolumn{2}{|c|}{38} & \multicolumn{2}{|c|}{38} \\
\hline Response & Yes & No & Yes & No & Yes & No \\
\hline Frequency & 9 & 28 & 21 & 15 & 23 & 12 \\
\hline Percentage & 23.7 & 76.3 & 58.3 & 41.7 & 65.7 & 34.3 \\
\hline Total (n) & \multicolumn{2}{|c|}{38} & \multicolumn{2}{|c|}{36} & \multicolumn{2}{|c|}{35} \\
\hline Mefloquine & \multicolumn{2}{|c|}{ Daily } & \multicolumn{2}{|c|}{2 Weeks } & \multicolumn{2}{|c|}{4 Weeks } \\
\hline Response & Yes & No & Yes & No & Yes & No \\
\hline Percentage & 54.1 & 45.9 & 63.2 & 36.8 & 59.5 & 40.5 \\
\hline Total $(\mathrm{n})$ & \multicolumn{2}{|c|}{37} & \multicolumn{2}{|c|}{38} & \multicolumn{2}{|c|}{37} \\
\hline Atovaquone + Proguanil & \multicolumn{2}{|c|}{ Weekly } & \multicolumn{2}{|c|}{1 Day } & \multicolumn{2}{|c|}{1 Week } \\
\hline Response & Yes & No & Yes & No & Yes & No \\
\hline Frequency & 20 & 18 & 23 & 17 & 25 & 13 \\
\hline Percentage & 52.6 & 47.4 & 57.5 & 42.5 & 65.8 & 34.2 \\
\hline Total (n) & \multicolumn{2}{|c|}{38} & \multicolumn{2}{|c|}{40} & \multicolumn{2}{|c|}{38} \\
\hline
\end{tabular}

\section{Authors' Contributions}

All authors contributed equally to this study.

\section{Conflicts of Interest Disclosures}

The authors declare that there is no conflict of interest.

\section{Ethical Approval}

Ethical approval was obtained from the Institutional Review Board of the MoPH (Doha, Qatar) as well as the relevant authorities of the participating healthcare facilities.

\section{Funding/Support}

None.

\section{Acknowledgments}

We would like to thank our colleagues in the MoPH and the PHCC for their insight and expertise. We also thank Miss Aya Mahmud for her assistance with the revision of the methodology and statistics sections and for the overall revision of the manuscript.

\section{References}

1. World Health Organization. World Malaria Report 2017. Geneva: World Health Organization; 2017.

2. Malaria Risk Assessment for Travelers. The Centers for Disease Control and Prevention (CDC) website. https://www.cdc.gov/ malaria/travelers/vfr.html. Published 2017.

3. Loutan L. Malaria: still a threat to travellers. Int J Antimicrob Agents. 2003;21(2):158-163.doi:10.1016/S0924-8579(02)00367-9.

4. Iqbal J, Hira PR, Al-Ali F, Sher A. Imported malaria in Kuwait (1985-2000). J Travel Med. 2003;10(6):324-329. doi:10.2310/7060.2003.9291.

5. Ismaeel AY, Senok AC, Jassim Al-Khaja KA, Botta GA. Status of malaria in the Kingdom of Bahrain: a 10-year review. J Travel Med. 2004;11(2):97-101. doi:10.2310/7060.2004.17059.

\section{Research Highlights}

What Is Already Known?

Imported malaria has been increased over the last 5 years, in Qatar, but evidence is limited to the knowledge of malaria chemoprophylaxis among physicians in the country.

\section{What This Study Adds?}

This study represents baseline data describing the knowledge of healthcare providers in Qatar, regarding travel-related malaria chemoprophylaxis. The important data provided by this article includes but is not restricted to the following:

1. Sociodemographic data of the participating physicians, their knowledge of malaria and its risk of transmission during travel, symptomatology of malaria, preventive strategies, and chemoprophylaxis.

2. This is the first study in the State of Qatar to develop a scoring system for evaluating the knowledge of physicians on malaria chemoprophylaxis among travelers to Qatar. 3. The study highlights several areas of practical knowledge of travel-related malaria prophylaxis and prevention among physicians in Qatar, as well as, few knowledge gaps that require mitigation through training programs on malaria prevention in travelers.

6. Meleigy M. The quest to be free of malaria. Bull World Health Organ. 2007;85(7):507-508. doi:10.2471/BLT.07.020707.

7. Beljaev AE. [The malaria situation in the WHO eastern Mediterranean region]. Med Parazitol (Mosk). 2000(2):12-15.

8. Snow RW, Amratia P, Zamani G, et al. The malaria transition on the Arabian Peninsula: progress toward a malaria-free region between 1960-2010. Adv Parasitol. 2013;82:205-251. doi:10.1016/b978- 
0-12-407706-5.00003-4.

9. World Health Organization. World Malaria Report 2011. http:// www.who.int/malaria/world_malaria_report_2011/en/. Accessed August 8, 2017. Published 2011.

10. Shibl A, Senok A, Memish Z. Infectious diseases in the Arabian Peninsula and Egypt. Clin Microbiol Infect. 2012;18(11):10681080. doi:10.1111/1469-0691.12010.

11. Al-Kuwari MG. Epidemiology of imported malaria in Qatar. J Travel Med. 2009;16(2):119-122. doi:10.1111/j.17088305.2008.00285.x.

12. Khan FY, Lutof AK, Yassin MA, et al. Imported malaria in Qatar: a one year hospital-based study in 2005. Travel Med Infect Dis. 2009;7(2):111-117. doi:10.1016/j.tmaid.2009.01.003.

13. Ministry of Public Health. MOPH Annual Report Public 2016. Qatar: MOPH; 2017.

14. Mikhail MW, Al-Bursheed KM, Abd El-Halim AS, Morsy TA. Studies on mosquito borne diseases in Egypt and Qatar. J Egypt Soc Parasitol. 2009;39(3):745-756.

15. Recommendations for Immigrants from Malaria-Endemic Countries Planning to Return "Home" to Visit Friends and Relatives. The Centers for Disease Control and Prevention (CDC) website. https:// www.cdc.gov/malaria/travelers/vfr.html. Published 2017.

16. Schwartz E. Prophylaxis of malaria. Mediterr J Hematol Infect Dis. 2012;4(1):e2012045. doi:10.4084/mjhid.2012.45.

17. Krause G, Schoneberg I, Altmann D, Stark K. Chemoprophylaxis and malaria death rates. Emerg Infect Dis. 2006;12(3):447-451. doi:10.3201/eid1205.050736.

18. Chaves TD, Monteiro WM, Alves JR, Lacerda M, Lopes MH. Pretravel malaria chemoprophylaxis counselling in a public travel medicine clinic in Sao Paulo, Brazil. Malar J. 2017;16(1):64. doi:10.1186/s12936-017-1713-3.

19. World Health Organization EMRO. Malaria Control and Elimination - Malaria country profiles (Qatar). http://www.emro. who.int/malaria/publications/malaria-country-profiles-2012.html. Accessed August 8, 2017. Published 2012.

20. Mace KE, Arguin PM. Malaria Surveillance - United States, 2014. MMWR Surveill Summ. 2017;66(12):1-24. doi:10.15585/mmwr. ss6612a1.

21. Chen LH, Wilson ME, Schlagenhauf P. Prevention of malaria in long-term travelers. JAMA. 2006;296(18):2234-2244. doi:10.1001/ jama.296.18.2234.

22. Stoney RJ, Chen LH, Jentes ES, et al. Malaria Prevention Strategies: Adherence Among Boston Area Travelers Visiting Malaria-Endemic Countries. Am J Trop Med Hyg. 2016;94(1):136-142. doi:10.4269/ ajtmh.15-0565.

23. Fernando SD, Dharmawardana $P$, Semege $S$, et al. The risk of imported malaria in security forces personnel returning from overseas missions in the context of prevention of re-introduction of malaria to Sri Lanka. Malar J. 2016;15(1):144. doi:10.1186/ s12936-016-1204-y.

24. Mawhorter SD. Travel medicine for the primary care physician. Cleve Clin J Med. 1997;64(9):483-492.

25. Keystone JS, Dismukes R, Sawyer L, Kozarsky PE. Inadequacies in Health Recommendations Provided for International Travelers by North American Travel Health Advisors. JTravel Med. 1994;1 (2):7278. doi:10.1111/j.1708-8305.1994.tb00566.x.

26. Hoveyda N, McDonald P, Behrens RH. A Description of Travel Medicine in General Practice: A Postal Questionnaire Survey. J Travel Med. 2004;11(5):295-299. doi:10.2310/7060.2004.19105.

27. Huang HL, Chiu TY, Huang KC, Cheng SY, Yao CA, Lee LT. Travelrelated mosquito-transmitted disease questionnaire survey among health professionals in Taiwan. J Travel Med. 2011;18(1):34-38. doi:10.1111/j.1708-8305.2010.00483.x.

28. Ropers G, Krause G, Tiemann F, Du Ry van Beest Holle M, Stark K. Nationwide survey of the role of travel medicine in primary care in Germany. J Travel Med. 2004;11(5):287-294.

29. Pavli A, Lymperi I, Katerelos P, Maltezou HC. Knowledge and practice of malaria prophylaxis among travel medicine consultants in Greece. Travel Med Infect Dis. 2012;10(5-6):224-229. doi:10.1016/j.tmaid.2012.09.006.

30. Chiodini J. The standard of malaria prevention advice in UK primary care. Travel Med Infect Dis. 2009;7(3):165-168. doi:10.1016/j. tmaid.2009.02.003.

31. Porter JF, Knill-Jones RP. Quality of travel health advice in higher-education establishments in the United Kingdom and its relationship to the demographic background of the provider. J Travel Med. 2004;11(6):347-353. doi:10.2310/7060.2004.19202. 